\title{
Voluntary informed consent and good clinical practice for clinical research in South Africa: Ethical and legal perspectives
}

\author{
Retha Britz, Andra le Roux-Kemp
}

Most differences, shortcomings and contradictions regarding voluntary informed consent for participation in clinical research relate to the South African-specific guidance documents, i.e. South African Guidelines for Good Practice in the Conduct of Clinical Trials with Human Participants in South Africa (2006) and Ethics in Health Research: Principles, Structures and Processes (2004). These documents do not fulfil all the ethical and legal requirements for voluntary informed consent for clinical research participation in South Africa. International guidance documents reflect the minimum of the ethical requirements for the conduct of clinical research. Country-specific documents should be updated and aligned with relevant legislative and legal principles of that jurisdiction to ensure that research participants are adequately protected. The South African-specific guidance documents therefore require revision to address these deficiencies.

S Afr Med J 2012;102(9):746-748. DOI:10/7196.SAMJ.5498
Voluntary informed consent for participation in clinical research is the cornerstone of health research ethics and a requirement for clinical research in South Africa. The South African-specific guidance documents concerning voluntary informed consent provisions differ and sometimes contradict international documents applicable in South Africa. With the provisions of the Constitution of South Africa (1996) and applicable legislation, it is apparent that voluntary informed consent provisions in the guidance documents are not always aligned with the relevant legislation and constitutional principles regarding informed consent.

The SA GCP guideline (South African Guidelines for Good Practice in the Conduct of Clinical Trials with Human Participants in South Africa) $)^{1}$ requires that it should always apply even where it differs from the other guidance documents (at section 1.3, p. 12). However, is the SA GCP guideline the ultimate and correct authority regarding voluntary informed consent, and are its voluntary informed consent provisions in line with governing legislation and the supreme Constitution of South Africa of 1996?

To ascertain the extent of similarities and differences in the guidance documents relevant to clinical research in South Africa, we compared the following documents: International Conference on Harmonisation: E6 Consolidated Guidelines for Good Clinical Practice, 1996 (ICH GCP); ${ }^{2}$ SA GCP 2006; ${ }^{1}$ Declaration of Helsinki (2004) as incorporated in SA GCP 2006 (World Medical Association at its 55th General Assembly, Tokyo, 2004); ${ }^{3}$ Declaration of Helsinki (2008) (World Medical Association at its 59th General Assembly, Seoul, 2008); ${ }^{4}$ Ethics in Health Research: Principles, Structures and Processes (Department of Health 2004 - 'ethical guidelines' for the purpose of this paper); ${ }^{5}$ the Constitution of the Republic of South Africa (1996); ${ }^{6}$ and the National Health Act 61 of 2003. ${ }^{7}$ The HPCSA's booklet 6, General Ethical Guidelines for Health Researchers (2008), ${ }^{8}$ although not discussed, provides valuable guidance on ethical behaviour in research.

Department of Public Law, Stellenbosch University, Western Cape Retha Britz, MSc (Physiology), MPhil (Applied Ethics) Andra le Roux-Kemp, BA LLB, LLD

\section{Informed consent in South Africa contextualised}

The doctrine of informed consent originated in 1957 in the case of Salgo $v$ Leland Stanford Jr. University Board of Trustees 317 P.2d 170 (Cal. Dist. Ct. App. 1957). ${ }^{9}$ This doctrine is about patient autonomy and self-determination and was first introduced in South Africa in 1976 in the case of Richter and another v Estate Hammann 1967 (3) SA 226 (C). ${ }^{10}$ Seventeen years later, in Castell v De Greef 1994 (4) SA $408(C)^{11}$ the doctrine was secured in South African medical and health law jurisprudence. ${ }^{12}$ Self-determination and the rights to bodily integrity and autonomous moral agency are now accepted as fundamental rights of every patient, and it is also accepted that health workers have a legal duty to obtain a patient's informed consent for any medical intervention. 'The best interests of the patient' cannot prevail above patient autonomy and self-determination, and informed consent requires a patient to fully appreciate the nature and extent of the harm or risk inherent in the intervention. ${ }^{11,12}$

The doctrine of informed consent is codified in sections 6, 7 and 8 of the National Health Act. The Act sets out the nature and scope of the information that should be disclosed to the patient, that it should be done in a language that the patient understands, and that the patient's level of literacy should be taken into account. The Act provides for patients' rights to self-determination and that their informed consent is required even if they were treated previously and the necessary consent was obtained then. It reiterates the right to self-determination that protects every person's right to bodily and psychological integrity and the right to security and control over their body as enshrined in the Constitution (section 12).

No judgment on informed consent has been handed down since the National Health Act was enacted. Cases in South African medical law, McDonald $v$ Wroe 2006 (3) All SA 565 (C) ${ }^{13}$ and Louwrens $v$ Oldwage 2006 (2) SA 161 (SCA), ${ }^{14}$ also pay no attention to the provisions of the National Health Act (then Bill). The National Health Act provides for research on or experimentation on human subjects and is therefore central to good practice in clinical trials. Sections 6, 8 and 71 are important for informed consent in clinical trials. Informed consent and the constitutional right to self-determination in a clinical setting underscore the relationship between research participant and researcher.

\section{Voluntariness}

Valid informed consent must be voluntary in clinical trials but can be influenced by two factors. The first is non-controlling factors 
like pain, psychological factors such as altruism or social and economic situations like poverty. Prospective participants may also be influenced by the power difference between themselves and the research investigators that threaten truly voluntary, valid informed consent. Another factor is when a treatment option for a condition is only available as part of a research trial and is not available in the private or public health sectors. Truly voluntary participation in such a trial is questionable. ${ }^{15}$ Controlling factors that influence voluntariness include persuasion, manipulation and coercion to participate in research. ${ }^{16}$

The influence of controlling factors on voluntary informed consent in clinical research and participatory decision-making deserves special attention in South Africa. Participatory decisionmaking refers to situations where individuals other than the research participant partake in the decision whether the participant should enrol for the clinical research trial. The Declaration of Helsinki 2008 explicitly provides for the participant to consult family members or community leaders on research participation. The ethical guidelines imply this communitarian world view that informed consent should be obtained with an 'understanding of the participant's world view or value system'. Yet, despite the opportunity of consulting with others, the prospective participant makes the final autonomous decision.

Researchers should therefore respect the research participant's decision to consult family members and community leaders and not assume that they have the same world view and values of their community. ${ }^{17}$ While the ethical guidelines recognise that community involvement should only be allowed with explicit consent of the prospective participant, no other guidance documents refer to this or address the potential risks and problems that may result because of participatory decision-making. Therefore, this shortcoming in the guidance documents requires attention as participatory decisionmaking is especially important for clinical research in Africa and with indigenous communities. (The National Health Research Ethics Council (NHREC) issued separate guidelines in 2011 on the role of community advisory groups in health research ethics and how communities should be engaged in research.)

A serious discrepancy in the SA GCP and ICH GCP compared with the general purport and object of voluntary informed consent in the National Health Act, in section 12 of the Constitution (1996) and in case law, deals with a research participant electing to withdraw from a clinical trial. The ICH GCP and SA GCP require that although a research participant is not obliged to give his/her reason(s) for withdrawing prematurely from a trial, the researcher should attempt to ascertain the reasons while fully respecting the participant's rights. This requirement is a contradiction, as it does not fully respect the participant's wishes and voluntary decision to withdraw from the clinical trial prematurely. The participant may feel threatened by the researcher attempting to obtain a reason for the withdrawal from the study, and may for this reason decide not to withdraw. Respect for participants and their autonomous rights do not end when they sign consent. Allowing a participant to decline consent or to withdraw from research participation without a reason is respectful of their rights. ${ }^{17}$ The GCPs in this regard contradict the notion of voluntary participation.

\section{Providing adequate information and the concept of being informed}

Another difference in the guidance documents is that the Declaration of Helsinki 2004 and 2008 and the ethical guidelines (in section 2.6) require that the prospective participant understands (or comprehends) the provided information before deciding on participation. Pivotal for autonomy is the process to adequately inform prospective participants about the research and to assess their understanding of the information provided. Personal autonomy is self-rule that is free from controlling influences by others and limitations, such as inadequate understanding, that prevent a meaningful and informed choice. ${ }^{17}$ The GCPs, however, do not require comprehension by the participant.

Ethically, for an action to be autonomous it must be substantially understood and full understanding of all aspects of the research is not needed. ${ }^{17}$ The minimum that should be understood is what the researcher believes a prospective participant should understand to authorise the action. ${ }^{17} \mathrm{~A}$ professional standard or medical judgement on whether adequate information was disclosed and whether the patient/participant truly comprehended is therefore the appropriate biomedical ethics standard. However, this is not sufficient in terms of South African (and international) legal precedent.

Initially cases on informed consent did little to clarify the farreaching authority of physicians regarding their discretion when disclosing information to a patient or research participant. Whether adequate information was disclosed and the patient/participant truly comprehended remained a matter of medical judgement in which thorough patient self-determination had no place. ${ }^{18}$ In Castell $v$ De Greef, however, a subjective patient-centred test for disclosure was used - a health worker or researcher should disclose all information and risks that a reasonable person in the patient's/ prospective participant's position would be able to attach significance to. ${ }^{11,19}$

This subjective patient-centred test was affirmed in Broude $v$ McIntosh 1998 (3) SA 60 (SCA) ${ }^{20}$ and McDonald $v$ Wroe 2006 (3) All SA 565 (C). It is also incorporated in sections $6-8$ and 71 of the National Health Act and is in line with the constitutional right to self-determination. However, the Supreme Court of Appeal erred in the case of Louwrens $v$ Oldwage 2006 (1) All SA 197 (SCA) in that the subjective patient-centred test for disclosure was accepted in the court a quo, but the court of appeal applied the dictum from the 1976 Richter case which required a professional standard (medical judgement) for disclosure. ${ }^{19,21} \mathrm{~A}$ serious legal shortcoming of the GCPs is therefore their lack of address and general ignorance regarding the appropriate standard to be applied when considering whether adequate information was disclosed and whether that particular patient/participant truly understood the information before deciding on research participation.

A once-off meeting with the researcher may be insufficient for the prospective participant to comprehend the research, since informed consent requires sufficient time for understanding. ${ }^{17}$ Also, a once-off consent does not constitute consent for the duration of the research study, especially if it is long-term, because participants may change their mind during the study and may wish to withdraw consent. When new information becomes available during the research, this must be disclosed to participants for them to reconsider their further participation. Therefore, continuous efforts should be made to ensure that participants' wishes regarding continuation are respected. ${ }^{15}$ Since informed consent requires ongoing dialogue between patient and health worker, a serious shortcoming is that none of the guidance documents we considered contains such provisions.

\section{Consent language}

Language barriers are common in a culturally diverse country like South Africa, especially with regard to prospective participants' full understanding of technical information. ${ }^{22}$ Besides potential problems with illiterate or uneducated prospective participants, their home language (as required by section 2.14 of the ethical guidelines) may also differ from the researcher's. The National 
Health Act demands that informed consent be obtained in a language that users understand and takes into account their literacy level. On the other hand, SA GCP 1.2.8 calls for consent to be obtained in the participant's language of choice, which may differ from the participant's home language. Giving participants a language choice in which the informed consent must be obtained (verbally and in writing) recognises the unique obstacles and needs of multi-lingual communities.

Ethically and legally, the language used to discuss informed consent and the informed consent document must be one that participants choose and feel comfortable with rather than insisting on their home language. No guidance document clarified whether the consent language refers to the verbal discussion or whether the written informed consent/assent documents should also be available in that language. It has been assumed that consent/assent documents should be available in the same language in which the verbal consent discussion takes place, but this is not required in the guidance documents considered.

\section{Number of signed copies of the informed consent document}

The number of signed copies of the informed consent document required differs significantly; ICH GCP 5.18.4(e) requires two while SA GCP 3.5 requires three. Other research guidance documents and the governing legislation do not address this aspect. The GCPs are not clear whether a copy refers to an original signed copy, a copy of the original signed copy or a certified copy thereof. Legally, according to section 221 of the Criminal Procedure Act No 51 of $1977^{23}$ and section 33 of the Civil Proceedings Evidence Act No 25 of $1965,{ }^{24}$ only one original signed copy of the informed consent document serves as the original; all others should be certified by a commissioner of oaths. While this is not required by the GCPs and may be impractical in clinical research, it is legally futile to require more signed copies than the original signed copy. We recommend that if more copies are required, e.g. for participant reference, certified copies should be made or an unsigned copy given to the participant, because the original signed informed consent document must remain at the research site.

\section{References}

1. South African Guidelines for Good Practice in the Conduct of Clinical Trials with Human Participants in South Africa (2006) (SA GCP 2006).

2. ICH GCP (International Conference on Harmonisation: E6 Consolidated Guidelines for Good Clinical Practice, 1996).

3. Declaration of Helsinki (2004) as incorporated in SA GCP 2006 (World Medical Association at its 55th Geclaration of Helsinki (2004) as
General Assembly, Tokyo, 2004).

General Assembly, Tokyo, 2004).
Declaration of Helsinki (2008) (World Medical Association at its 59th General Assembly, Seoul, 2008). 4. Declaration of Helsinki (2008) (World Medical Association at its 59th G
5. Ethics in Health Research: Principles, Structures and Processes (2004).

6. Constitution of the Republic of South Africa (1996)

7. National Health Act 61 of 2003

8. HPCSA's booklet 6, General Ethical Guidelines for Health Researchers (2008).

9. Salgo v Leland Stanford Jr. University Board of Trustees 317 P.2d 170 (Cal. Dist. Ct. App. 1957).

10. Richter and another v Estate Hammann 1967 (3) SA 226 (C).

11. Castell v De Greef 1994 (4) SA 408 (C) 420J, 421C-D \& 427D-E.

12. Le Roux-Kemp A. Law, Power and the Doctor-Patient Relationship. Saarbrücken: VDM Publishing House, 2011:92-93.

13. McDonald v Wroe 2006 (3) All SA 565 (C).

14. Louwrens $v$ Oldwage 2006 (2) SA 161 (SCA)

15. Mystakidou K, Panagiotou I, Katsarangakis S, Tsilika E, Parpa E. Ethical and practical challenges in implementing informed consent in HIV/AIDS clinical trials in developing or resource-limited in implementing informed consent in HIV/AIDS clinical trials in developing or resource-limited
countries. Journal of Social Aspects of HIV/AIDS 2009;6(2):46-56, 50. [http://dx.doi.org/10.1080/1 7290376.

16. Moodley K, ed. Medical Ethics, Law and Human Rights. Pretoria: Van Schaik, 2011.

17. Beauchamp TL, Childress JF. Principles of Biomedical Ethics. 5th ed. Oxford: Oxford University Press, 2001.

18. Le Roux-Kemp A. Law, Power and the Doctor-Patient Relationship. Saarbrücken: VDM Publishing House, 2011:58-123.

19. Thomas R. Where to from Castell v De Greef? Lessons from recent developments in South Africa and abroad regarding consent to treatment and the standard of disclosure. South African Law Journal 2007;188-215.

20. Broude v McIntosh 1998 (3) SA 60 (SCA).

21. Le Roux-Kemp A. Law, Power and the Doctor-Patient Relationship. Saarbrücken: VDM Publishing House, 2011:99-100.

22. Andrews S. Informed consent and HIV: a review of the topic with reference to the particular problems posed by the HIV pandemic: legal and ethical issues. Southern African Journal of HIV Medicine 2001;2(3):12.

23. Criminal Procedure Act 51 of 1977 .

24. Civil Proceedings Evidence Act 25 of 1965

Accepted 9 July 2012.

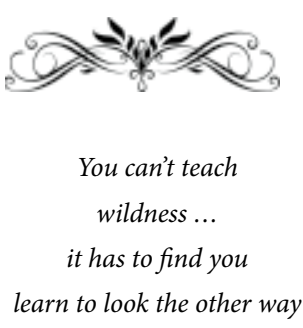

From 'Untamed'

Ian McCallum soitgoes@iafrica.com 